\title{
A Composite Based On Epoxy Polymer and Carbon Nanotubes: Structure, Optical Properties and Interaction with Microwave Radiation
}

\author{
F.F. Komarov ${ }^{1}$, A.G. Tkachev², O.V. Milchanin ${ }^{1}$, I.D. Parfimovich ${ }^{3}$, \\ M.V. Grinchenko ${ }^{3}$, I.N. Parkhomenko ${ }^{3}$, D.S. Bychenok ${ }^{4,5}$ \\ ${ }^{1}$ Department of Elionics, A.N. Sevchenko Institute of Applied Physical Problems of Belarusian State University, \\ 7, Kurchatova St., Minsk, 220045, Belarus \\ ${ }^{2}$ Department of Technology and Methods of Nanoproducts Manufacturing, Tambov State Technical University, \\ 1, Leningradskaya St., Tambov, 392000, Russia \\ ${ }^{3}$ Department of Radiophysics and Computer Technologies, Belarusian State University, \\ 4, Nezavisimosti Ave., Minsk, 220030, Belarus \\ ${ }^{4}$ Department of NanoElectroMagnetics, Institute for Nuclear Problems of Belarusian State University, \\ 11, Bobruiskaya St., Minsk, 220030, Belarus \\ ${ }^{5}$ Department of Electronics, Ryazan State RadioEngineering University, \\ 59/1, Gagarina St., Ryazan, 390005, Russia \\ * Corresponding author: Tel.: +375 1721248 33; E-mail: KomarovF@bsu.by
}

\begin{abstract}
A method for dispersing multi-walled carbon nanotubes in a SpeciFix-20 two-component polymer (epoxy resin + hardener) using joint hydromechanical and ultrasonic agitation was developed. New composite materials with carbon nanotubes were produced. Studies on structural, optical (Raman spectra) and electrical characteristics, as well as processes of passage of electromagnetic microwave radiation $(26-38 \mathrm{GHz})$ through experimental composite samples were conducted. It was shown that strong absorption properties of the composite materials are manifested only with substantial weight additives of the multi-walled carbon nanotubes due to the electrical conductivity of the composites. The "size effect" of the additive type on the optical characteristics of the obtained composite materials was found. To achieve comparable parameters of microwave absorption coefficients, fewer amounts of carbon nanotubes with smaller diameter and larger specific surface area should be introduced into the composites.
\end{abstract}

\section{Keywords}

Carbon nanotubes; composite materials; epoxy resin; microwave radiation; structural, optical and electrical properties of composites.

(C) F.F. Komarov, A.G. Tkachev, O.V. Milchanin, I.D. Parfimovich, M.V. Grinchenko, I.N. Parkhomenko, D.S. Bychenok, 2017

\section{Introduction}

The first detailed description of the structure of hollow carbon fibers was performed in 1991 by S. Iijima in his work devoted to the synthesis of a new allotropic carbon modification using the arc method [1]. This discovery has attracted the attention of specialists from around the world, and the topic of studying the unique physical properties of carbon nanotubes (CNTs) nowadays is one of the most popular in the scientific world. The discovery and synthesis of CNTs has stimulated intensive research on determining the potential for their applications due to their unique properties such as mechanical and electrical ones $[2,3]$. It is known that CNTs possess an extremely high mechanical strength (the Young's modulus of $2 \mathrm{TPa}$ ) and elasticity, high thermal conductivity $(2000 \mathrm{~W} / \mathrm{mK})$, high electric strength, ability to pass current of up to $10^{10} \mathrm{~A} / \mathrm{cm}^{2}$, and high electron mobility. CNTs may act as semiconductors or metals, depending on their diameter and structural chirality. These features are of significant scientific 
interest and can be used as a basis for effective application of nanotubes in various fields of science and technology.

However, it is difficult to work with single CNTs due to their small sizes and strong interaction with electric and magnetic fields. These issues may be overcome by creating CNTs-based macroscopic materials. Therefore, the topic of novel composite materials containing carbon nanomaterials within a matrix thereof is currently under intensive development. In recent years, studies have been widely conducted in this field; they involve various composite materials and, especially, polymers with the addition of $1-10$ wt. $\%$ of CNTs [4 - 13]. Even small amounts of CNTs significantly alter the properties of polymers: strength, thermal conductivity increases, and electrical conductivity occurs. Imparting the conductive properties to polymers (which almost always act as good electrical insulators) by the addition of CNTs seems to be highly attractive. It is noteworthy that the percolation threshold, at which the electrical conductivity of a polymer composite increases, is extremely small when adding single-walled CNTs (SWCNTs) at a level of $0.1 \mathrm{wt} \%$. At such CNT concentrations, all other polymer properties remain unchanged or change insignificantly. These materials are also promising for using as protective coatings to shield unique electronic systems against electromagnetic radiation (EMR) in the microwave range [4], including spacecraft systems. Currently, there is a great interest in the studies on absorption process and reflection of EMR of polymers with CNTs in a wide range of wavelengths [5, 14, 15]. Furthermore, there is an opportunity to create transparent and conductive coatings, electrostatic protection, electrostatic paints, coatings for shielding electrical noise and absorption of microwave power. In several studies, the development of novel carbon nanostructures-based multi-functional composites, including composite radiomaterials, able to substantially weaken EMR has been reported [16 - 19]. An increase in the level of microwave radiation and the so-called "electromagnetic environmental pollution" explains the interest in the development of such materials. Besides, the use of polymers as a matrix for CNTs will considerably improve the physical and mechanical properties of shielding materials such as elasticity and resistance to external influences, sufficiently maintaining the shielding properties compared with materials which directly consist of CNTs [7, 13].

Currently, to create new composite materials with unique optical, physical and mechanical characteristics for using in modern production technologies, several requirements should be considered. On the one hand, it is necessary to ensure desired properties and characteristics of composite materials. On the other hand, in order to quickly modify the properties of obtained composites to fit desired process parameters of final products, the technology for manufacturing such composites should be inexpensive, easily reproducible, and flexible. At the present time, the SWCNT production technology is rather expensive. And the material yield for this technology is not high, whereas the price of SWCNTs is tens-hundreds of dollars per gram. Therefore, for mass production of composite materials containing nanoscale carbon formations, it seems appropriate to employ inexpensive materials available in bulk quantity. They include commercially produced multi-walled carbon nanotubes (MWCNTs) and multi-graphene (polygraphene) materials.

\section{Experimental}

In the present research, a SpeciFix-20 optically transparent non-shrink two-component polymer (epoxy resin + hardener) was chosen as initial polymeric matrix to obtain composite samples. "Taunit"-series MWCNTs produced by "NanoTechCenter" Ltd (Tambov, Russia) were used as additives (fillers) to those samples. For comparison purposes, two types of the MWCNTs were chosen "Taunit" and "Taunit-M"; they have different geometric parameters (nanotube diameter, number of wall layers, bulk density, and specific surface area) (Fig. 1), which can affect the dispersion in the polymeric matrix and the characteristics of the synthesized composites. Table 1 presents the dimensional characteristics of the MWCNTs used herein.

The dispersion of the carbon nanomaterials in the epoxy resin was performed at an elevated temperature $\left(65^{\circ} \mathrm{C}\right)$ for $2-4 \mathrm{~h}$. The process included "quick" hydromechanical mixing (up to $2000 \mathrm{rpm}$ ) of the

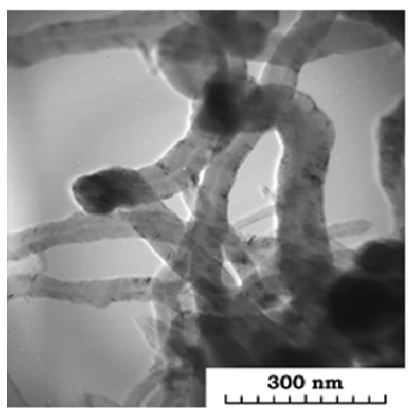

a)

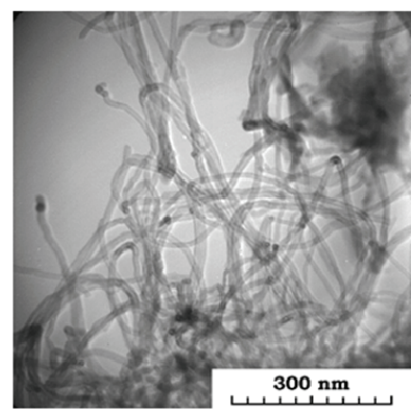

b)
Fig. 1. Bright-field TEM images of the MWCNTs: $a$ - "Taunit"; $b$ - "Taunit-M" 
Table 1

Dimensional characteristics of the MWCNTs used

\begin{tabular}{lcc}
\hline \multicolumn{1}{c}{ Parameters } & \multicolumn{2}{c}{ MWCNTs } \\
& "Taunit" & "Taunit-M" \\
\hline Outer diameter, nm & $20 \ldots 70$ & $8 \ldots 15$ \\
Inner diameter, $\mathrm{nm}$ & $5 \ldots 10$ & $4 \ldots 8$ \\
Length, $\mathrm{m}$ & $>2$ & $>2$ \\
Specific surface area, $\mathrm{m}^{2} / \mathrm{g}$ & $>120 \ldots 130$ & $>300 \ldots 320$ \\
\hline
\end{tabular}

components and simultaneous exposure of the mixture to ultrasound at a frequency of $35 \mathrm{kHz}$. The composite samples were prepared with different MWCNT contents. The maximum content of the MWCNT additives to the SpeciFix-20 matrix was found to be 16 and 8 wt. \% for "Taunit" and "Taunit-M", respectively. The thickness of the samples formed was $(15 \pm 1) \mathrm{mm}$.

The MWCNT structure was studied by a transmission electron microscopy (TEM) method. The results of this study were found to be in good agreement with data claimed by the manufacturer, thereby indicating good reproducibility in the "Taunit"-series MWCNT production.

To determine the optical characteristics of the composite materials in the microwave range (transmission effects, reflection and absorption of EMR), a R2-408R scalar network analyzer R2-408R, designed on the basis of a sweep generator, a waveguide measuring transmission line, an analyzer unit, and a signal processing system, was used. A detailed description of the installation procedure can be found in Ref. [20]. Measurements were carried out in the frequency range of $26-38 \mathrm{GHz}$. The composite samples under study were cut in the form of a parallelepiped, the dimensions of which were $7.2 \times 3.4 \times 1.5 \mathrm{~mm}^{3}$, corresponding to the size of the waveguide transmission line. The S-parameters of transmission $\left(S_{21}\right)$ and reflection $\left(S_{11}\right)$ were considered as output data. The transmission $\left(K_{T}\right)$, reflection $\left(K_{R}\right)$ and absorption $\left(K_{A}\right)$ coefficients were calculated as follows:

$$
\begin{aligned}
& K_{T}=\left(S_{21}\right)^{2} ; \\
& K_{R}=\left(S_{11}\right)^{2} ;
\end{aligned}
$$

$$
K_{A}=1-\left(S_{21}\right)^{2}-\left(S_{11}\right)^{2} .
$$

To evaluate the structural uniformity of the composite materials, optical microscopy combined with Raman spectroscopy was employed using a LOTISTII "Nanofinder High End" micro-Raman spectrometer. The Raman studies were performed in the backscattering geometry at a room temperature. A solid-state laser with a wavelength $(\lambda)$ of $473 \mathrm{~nm}$ acted as a radiation source. The laser beam was focused to a spot with a diameter of about $1 \mu \mathrm{m}$. During registration, diffraction gratings with 600 lines $/ \mathrm{mm}$ (spectral resolution - $0.01 \mathrm{~nm}$ ) and a highly sensitive $\mathrm{CCD}$ detector cooled down to $80{ }^{\circ} \mathrm{C}$ were used.

\section{Results and Discussion}

Figure 2 present the transmission, reflection and absorption coefficients found for the composite samples based on the SpeciFix-20 polymer with different MWCNT contents (1 - 16 wt. \% - "Taunit", and $1-8$ wt. \% - "Taunit-M").

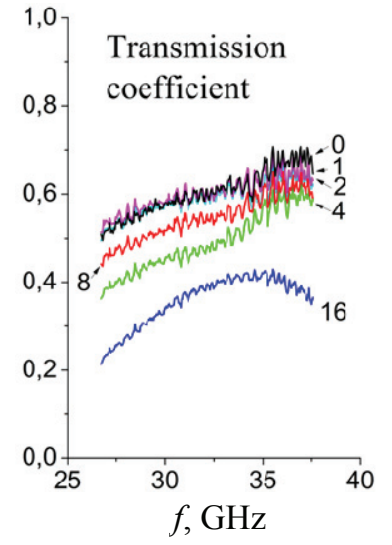

a)

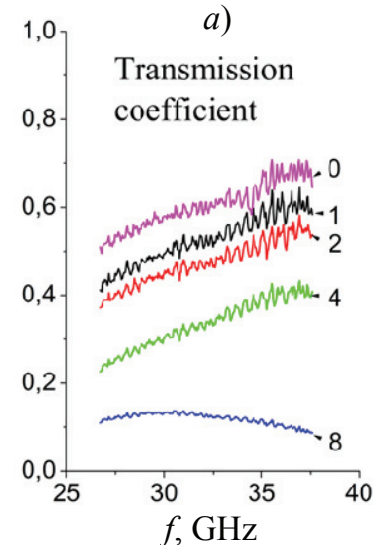

d)

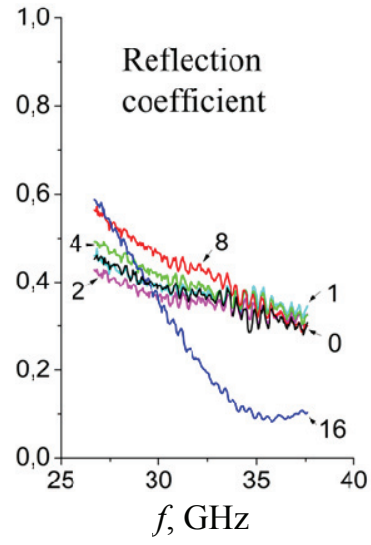

b)

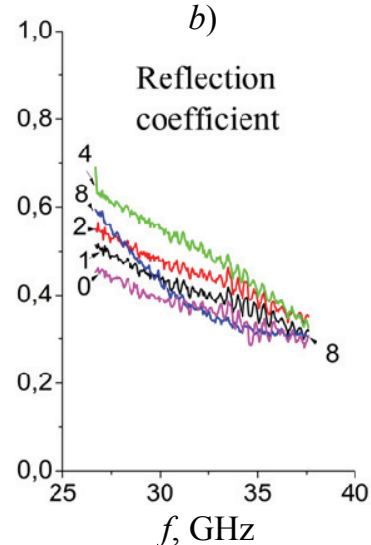

e)

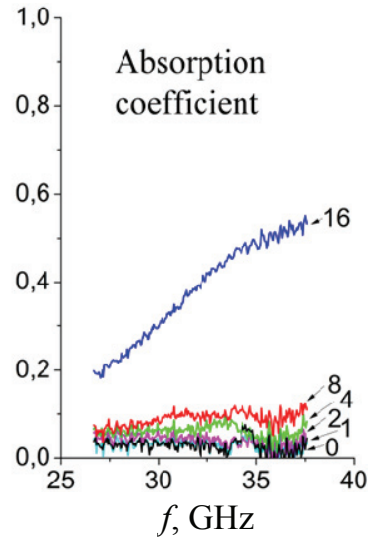

c)

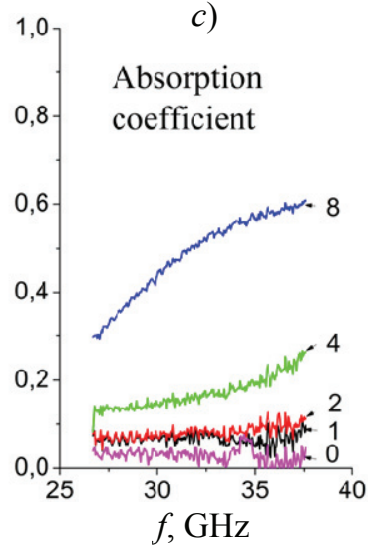

f)
Fig. 2. Transmission $(a, d)$, reflection $(b, e)$ and absorption $(c, f)$ coefficients of electromagnetic radiation $(26 \ldots 38 \mathrm{GHz})$ across/by the composite materials based on the epoxy resin modified with the "Taunit" MWCNTs (thickness of all the samples $-1.5 \mathrm{~mm}$ ):

0 - original epoxy resin; $1-1$ wt. \% MWCNTs; $2-2$ wt. \% MWCNTs; $4-4$ wt. $\%$ MWCNTs; $8-8$ wt. \% MWCNTs; $16-16$ wt. \% MWCNTs 
For the composite samples containing $1-8$ wt. \% of "Taunit", a monotonic decrease in the reflection function and an increase in the transmission function appear to be specific. At the maximum "Taunit" concentration (16 wt. \%), the transmission function in the polymer increases in the frequency range up to $34 \mathrm{GHz}$, and then decreases. For this sample, a sharper decrease in the reflection function at the frequencies of $33-38 \mathrm{GHz}$ can be observed - down to the values of less than $10 \%$. Due to these factors, the absorption coefficient for the composite material containing 16 wt. \% of "Taunit" has a high value. It should be noted that the absorption coefficient found for this sample greatly changes its value in the frequency range under study. It monotonously increases from $20 \%$ at $26.5 \mathrm{GHz}$ up to $53 \%$ at $37.5 \mathrm{GHz}$.

In the composite samples with "Taunit-M", a monotonic decrease in the transmission coefficient with increasing MWCNT concentrations takes place. Like in the case of the "Taunit" addition, the transmission monotonically increases with increasing frequency, and the reflection decreases. For the composite sample with 8 wt. \% of "Taunit-M", strong attenuation of the transmission (around 10\% throughout the frequency range) and a weak frequency dependence, along with a decrease in the reflection function, are observed. The absorption coefficients of the composites increase significantly with increasing "Taunit-M" concentrations. The maximum absorption coefficient values were recorded for the composite containing 8 wt. $\%$ of the additive. Like for the sample with $16 \mathrm{wt} . \%$ of "Taunit", in this case, the absorption coefficient changes from $30 \%$ at $26.5 \mathrm{GHz}$ up to $60 \%$ at $37.5 \mathrm{GHz}$.

Thus, a significant increase in the EMR absorption coefficients in the microwave range can be recorded for the composite materials at the maximum additive concentrations - up to the coefficient values of $50-60 \%$ (Figs. 2, b, f). At lower additive concentrations, a slight change in the transmission, reflection and absorption functions of the composites compared to the original polymer can be observed. From the analysis of the studies on the optical properties of the composites containing different MWCNT additives and given the structural characteristics of these additives, it can be concluded that a "size effect" of the additive type on the composite characteristics takes place. For the MWCNTs with a smaller diameter and larger specific surface area
("Taunit-M"), fewer additive amounts (almost twice as less) are required to achieve comparable absorption coefficient rates.

To study the morphology and assess the quality of the MWCNT dispersion in the synthesized composite materials, Raman spectra were recorded in combination with optical microscopy from different areas of the sample sections. For the original SpeciFix20 polymer samples, narrow bands typical of the vibrational modes of the atoms in the epoxy rings were registered in the Raman spectra (not shown herein). Sharp peaks at 2930 and $2880 \mathrm{~cm}^{-1}$ related to the aliphatic $\mathrm{C}-\mathrm{H}$ bonds and at $3073 \mathrm{~cm}^{-1}$ assigned to the $\mathrm{C}-\mathrm{H}$ aromatic bonds [21] can be observed. In the region of $600-1600 \mathrm{~cm}^{-1}$, less intense lines, related to the breathing modes of the epoxy rings and the deformation of the covalent bonds of the atoms (valent $\mathrm{C}-\mathrm{C}$ vibrations of the aromatic ring, deformation vibrations of the $\mathrm{C}-\mathrm{H}$ groups) inside the rings, can be seen [21-22]. In Fig. 3, the Raman spectra of the composite materials containing large MWCNTs amounts are presented. In these spectra, one can see a marked change in the EMR absorption characteristics. It was found that the MWCNTs-free areas take place at the sections of the samples containing even maximum (16 wt. \%) amount of the "Taunit" material, as evidenced by the results in

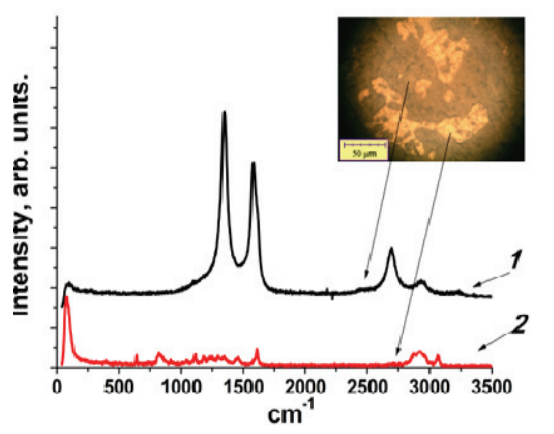

a)

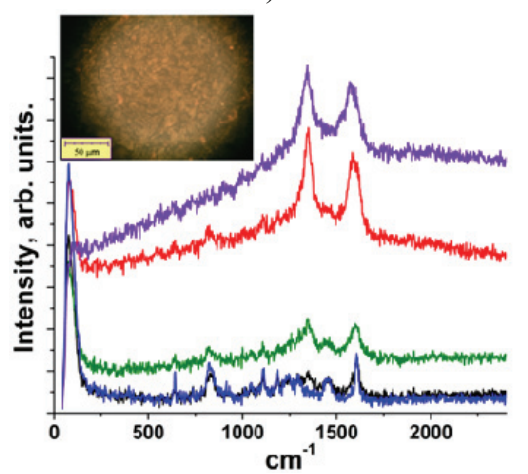

c)

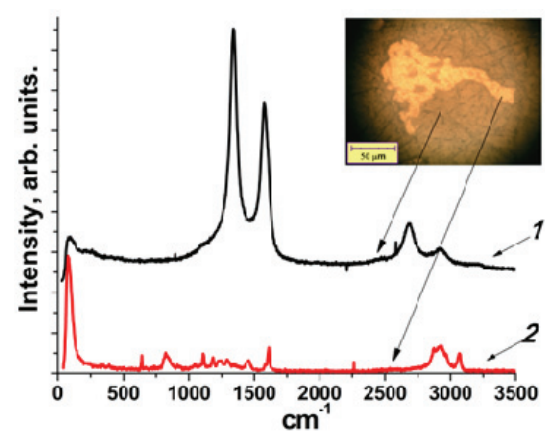

b)

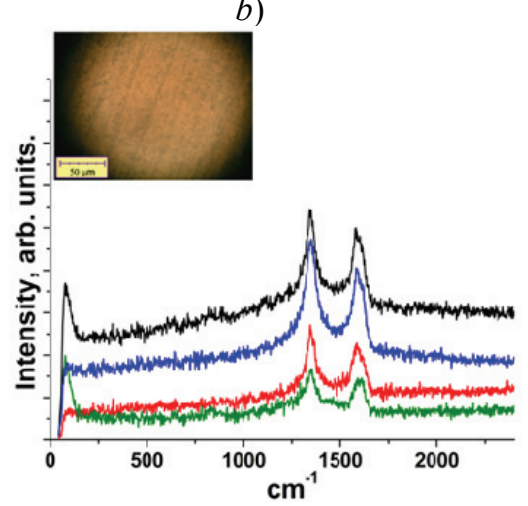

d)
Fig. 3. Raman spectra of the Specifix-20 composite materials with the additions of MWCNTs - "Taunit" (8 wt. \% - (a), 16 wt. \% - (b)), and "Taunit-M" $(4 \mathrm{wt} . \%-(c), 8$ wt. $\%-(D))$ - recorded from different sample areas. The insets show optical images of the area of the corresponding polymer sample (scale $-\mathbf{5 0} \mu \mathrm{m}$ ) 
(Figs. 3, $a, b$ ). On the optical images, there are light and dark contrast areas. The spectra taken from the light areas are completely identical with the abovedescribed spectra of the pure epoxy composites. The length of these (light) areas at the sections of the samples is up to $100 \mu \mathrm{m}$. In the Raman spectra taken from the dark areas, bands typical only of MWCNTs are registered [23-27]. These bands are intense $\sim 1350$ and $1580 \mathrm{~cm}^{-1}$. The band around $1580 \mathrm{~cm}^{-1}$ corresponds to the lattice vibrations of the $E_{2 g}$ symmetry in planes of the graphene layers with $\mathrm{sp}^{2}$-hybridized valence bonds [27]. It may differ in frequency and shape depending on the structural perfection of materials. The band at $1350 \mathrm{~cm}^{-1}$ is due to the D-band, which is usually related to small size of ordering areas and the availability of pronounced boundaries of carbon crystallites causing a violation of the wave vector selection rules for Raman scattering. Moreover, this band is present in spectra of all the carbon materials and appears to be a characteristic of their degree of defectiveness [28]. The less intense band around $\sim 2700 \mathrm{~cm}^{-1}$ is associated with two-phonon (secondorder) scattering and designated as $\mathrm{G}^{\prime}$-band (or 2D-band) [29].

For the composites containing the "Taunit-M" additives of up to $8 \mathrm{wt}$. \%, the areas of light contrast are also present on the optical images of the sections (Fig. 3, c). Nevertheless, the size of these areas is much less - from hundreds of $\mathrm{nm}$ to several $\mu \mathrm{m}$. For the composite material with 8 wt. \% of the "Taunit-M" material, a uniform contrast on the photos of the sections is typical. In this case (Fig. 3,d), at all the points of recording the Raman spectra, the D-band and G-band can be clearly seen at the sections, thereby evidencing good enough quality of the dispersion of this nanomaterial in the matrix.

Despite the presence of the MWCNTs-free zones in the samples, one can say that the composites represent a volumetric grid of areas with high MWCNT concentrations. As a rule, after having been produced, MWCNT materials have mixed conductivity of both metal and semiconductor types. At high MWCNT concentrations in the composite, even considering that the nanotubes lie inside the matrix as bulk clots and do not completely fill up the entire volume of the material, it can be assumed that the formation of bulk conducting channels, the interaction between which through the nano-sized regions of the dielectric matrix leads to significant conductivity of the entire composite, takes place. This is confirmed by the electrophysical studies. The results of measuring the specific conductivity of the composite materials on a frequency dielectric spectroscopy setup [30] are represented in Table 2.
Table 2

\section{Conductivity of the composite materials at room temperature (frequency of alternating current measurements $-50 \mathrm{~Hz}$ )}

\begin{tabular}{ccc}
\hline \multirow{2}{*}{$\begin{array}{c}\text { Percentage } \\
\text { of MWCNT } \\
\text { additive, wt. \% }\end{array}$} & \multicolumn{2}{c}{ Conductivity, S/m } \\
MWCNTs \\
\hline "Toriginal & $1.0 \cdot 10^{-13}$ & $1.0 \cdot 10^{-13}$ \\
polymer) & $4.83 \cdot 10^{-11}$ & $2.1 \cdot 10^{-10}$ \\
1 & $3.19 \cdot 10^{-11}$ & $1.6 \cdot 10^{-9}$ \\
2 & $2.77 \cdot 10^{-10}$ & $1.1 \cdot 10^{-9}$ \\
4 & $1.71 \cdot 10^{-9}$ & $1.17 \cdot 10^{-7}$ \\
8 & $3.7 \cdot 10^{-5}$ & - \\
16 & & \\
\hline
\end{tabular}

Increasing the MWCNT concentration in the composite materials leads to a monotonic increase in their conductivity. It should be noted that at the same additive concentrations, the composites with "Taunit-M" possess higher (almost one order of magnitude) conductivity than those with "Taunit". And the conductivity of the composite containing $16 \mathrm{wt} \%$ of the "Taunit" material grows by more than 7 orders of magnitude compared with the original epoxy polymer. For the composite with 8 wt. \% of "Taunit-M", the conductivity reaches almost 6 orders of magnitude.

Besides, the effect of strong EMR absorption by the composites with high MWCNT concentrations (8 wt. \% for "Taunit- M", and 16 wt. \% for "Taunit") is in good agreement with the sharp increase in their conductivity due to the formation of a bulk grid of conducting channels.

\section{Conclusion}

The effective method of dispersing MWCNTs in an epoxy polymer matrix, allowing for manufacturing composite materials able to significantly attenuate EMR in the microwave range, was developed. Optical studies of the synthesized composites were conducted EMR transmission, reflection and absorption coefficients were determined in the frequency range of $26 \ldots 38 \mathrm{GHz}$. It was found that at the MWCNT concentration of $16 \mathrm{wt} . \%$ in the composite samples, the EMR absorption coefficient reaches $55 \%$ at $38 \mathrm{GHz}$. The similar situation occurred for the composites samples with the addition of "Taunit-M". In this case, the strong absorption effect was recorded at the additive concentrations of $8 \mathrm{wt} . \%$ - the absorption coefficient increases up to $60 \%$ at $38 \mathrm{GHz}$. It is established that the geometric dimensions of the MWCNTs (smaller nanotubes diameter and, consequently, larger specific surface area) have 
a significant impact on the absorbing characteristics of the developed composites - to achieve the absorption effect by the composite samples, fewer MWCNT amounts are required. Besides, it was found that in the composite samples with the maximum "Taunit" concentration, an increase in the absorption coefficient (down to $55 \%$ ) occurs when sharply decreasing the reflection coefficient (below $8 \%$ ). And in the composites with the "Taunit-M" a drastic decrease in the EMR transmission coefficient (below $10 \%)$ takes place when increasing the absorption coefficient up to $60 \%$. It was shown that at high MWCNT concentrations in the epoxy-based composite, even considering that the nanotubes lie inside the matrix as clots, the formation of bulk conducting channels, the interaction between which through the nano-sized regions of the dielectric matrix leads to significant conductivity of the entire composite, takes place. This can explain the strong EMR absorption effect in the frequency range of $26-38 \mathrm{GHz}$ for the composites with the maximum concentrations of the MWCNTs ( 8 wt. \% for "Taunit-M" and 16 wt. \% for "Taunit").

\section{References}

1. Iijima S. Helical microtubes of graphitic carbon. Nature, 1991, vol. 354, pp. 56-58.

2. Dyachkov P.N. Uglerodnye nanotrubki. Stroenie, svoystva, primenenie [Carbon nanotubes. Structure, Properties, Application]. Moscow, Binom Publ., 2006, 293 p. (Rus)

3. Tkachev A.G., Zolotukhin I.V. Appparatura i metody sinteza uglerodnyh nanostruktur [Equipment and methods for synthesis of carbon nanostructures]. Moscow: Mashinostroenie - 1 Publ., 2007, 316 p. (Rus)

4. Hornbostel B., Leute U., Pötschke P., Kotz J., Kornfeld D., Chiu P.-W., Roth S. Attenuation of electromagnetic waves by carbon nanotube composites. Physica E, 2008, vol. 40, no. 7, pp. 2425-2429.

5. Lv R., Kang F., Gu J., Gui X., Wei J., Wang K., $\mathrm{Wu}$ D. Carbon nanotubes filled with ferromagnetic alloy nanowires: Lightweight and wide-band microwave absorber. Applied Physics Letters, 2008, vol. 93, no. 22, pp. $223105(1-3)$

6. Park S.H., Thielemann P., Asbeck P., Bandaru P.R. Enhanced dielectric constants and shielding effectiveness of, uniformly dispersed, functionalized carbon nanotube composites. Applied Physics Letters, 2009, vol. 94, no. 24, pp. 243111 (1-3).

7. Komarov F.F., Tkachev A.G., Munoz E., Milchanin O.V., Krivosheev R.M., Parhomenko I.N., Zhukovski P. [Effect of fabrication procedure on the electrical conductivity, electromagnetic shielding and optical properties of composites with carbon nanomaterials]. Mater. of the $1^{\text {st }}$ Intern. Conf. "Graphene and related structures: synthesis, production and use». Tambov, 2015, pp. 50-52. (Rus)
8. Komarov F.F., Tkachev A.G., Krivosheev R.M., Milchanin O.V. [Optical properties of PU enchanced with carbon nanomaterials]. Mater. of the $I^{\text {st }}$ Intern. Conf. "Graphene and related structures: synthesis, production and use». Tambov, 2015, pp. 200-202. (Rus)

9. Zhang H., Zeng G., Ge Y., Chen T., Hu L. Electromagnetic characteristic and microwave absorption properties of carbon nanotubes/epoxy composites in the frequency range from 2 to $6 \mathrm{GHz}$. Journal of Applied Physics, 2009, vol. 105, no. 5, pp. 054314 (1-4).

10. Komarov F.F., Krivosheev R.M., Ksenofontov M.A., Koltynowicz T.N., $\quad$ Abdullin H.A., $\quad$ Ostrovskaya L.E., Togombaeva A.K. Formirovanie kompozita na osnove poliuretana $\mathrm{s}$ uglerodnymi nanotrubkami i shungitom [Formation of the composite on the basis of polyurethane and carbon nanotubes and schungite]. Inzhinerno-fizicheskii zhurnal, 2015, vol. 88, no. 2, pp. 344-349. (Rus)

11. Komarov F.F., Ksenofontov M.A., Tkachev A.G., Krivosheev R.M., Ostrovskaya L.E., Rodionova V.N., Togombaeva A.K. [Influence of carbon nanomaterials on the structure, electrophysical properties of polyurethane and EMR shielding efficiency]. Doklady National'noi Akademii Nauk Respubliki Belarus, 2014, vol. 58, no. 4, pp. 42-46. (Rus)

12. Mouradian V.E., Sokolov E.A., Babenko S.D., Moravsky A.G. Dielektricheskie svoystva kompozitov, modificirovannykh uglerodnymi nanostrukturami $\mathrm{v}$ mikrovolnovom diapazone [Dielectric properties of composites, modified by carbon nanostructures in a microwave range]. Zhurnal tekhnicheskoi fiziki, 2010, vol. 80 , pp. 83-87. (Rus)

13. Komarov F.F., Zukowski P., Kryvasheyeu R.M., Munoz E., Koltunowicz T., Rodionova V.N.,Togambaeva A.K. Effects of surfactant and fabrication procedure on the electrical conductivity and electromagnetic shielding of single-walled carbon nanotube films. Phys. Status Solidi A, 2014, vol. 212, no. 2, pp. 425-432. doi: 10.1002/ pssa.201431493.

14. Ostrovsky O.S., Odarenko E.N., Shmat'ko A.A. Zaschitnye ekrany I poglotiteli eleltromagnitnykh voln [Shields and absorbers of electromagnetic waves]. Fizicheskaya inzhineria poverkhnosti, 2003, vol. 1, no. 2, pp. 161-173. (Rus)

15. Bychanok D., Kuzhir P., Maksimenko S., Bellucci S., Brosseau C. Characterizing epoxy composites filled with carbonaceous nanoparticles from de to microwave. Journal of Applied Physics, 2013, vol. 113, no. 12, pp. 124103 (1-6).

16. Komarov F.F., Milchanin O.V., Munoz E., Rodionova V.N., $\quad$ Karpovich V.B., Krivosheev R.M. Oslablenie elektromagnitnogo izluchenia SVCh-diapazona bumagoy iz uglerodnyh nanotrubok [Attenuation of electromagnetic radiation of SVCh-range with paper of carbon nanotubes]. Zhurnal tekhnicheskoi fiziki, 2011, vol. 81, no. 11, pp. 140-145. (Rus)

17. Vinoy K.L., Jha R. M. Radar Absorbing Materials from Theory to Design and Characterization. Boston: Kluwer Acad. Publ., 1996. 208 p.

18. Roberts J.A., Imholt T., Ye Z., Dyke C.A., Price Jr. D.W., Tour J.M. Electromagnetic wave properties 
of polymer blends of single wall carbon nanotubes using a resonant microwave cavity as a probe. Journal of Applied Physics, 2004, vol. 95, no. 8, pp. 4352-4356.

19. Bychanok D., Gorokhov G., Meisak D., Kuzhir P., Maksimenko S.A., Wang Y., Han Z., Gao X., Yue H. Design of carbon nanotube-based broadband radar absorber for ka-band frequency range. Progress in Electromagnetics Research M, 2017, vol. 53, pp. 9-16.

20. Bychanok D., Gorokhov G., Meisak D., Plyushch A., Kuzhir P., Sokal A., Lapko L., Sanchez-Sanchez A., Fierro V., Celzard A., Gallagher C., Hibbins A.P., Ogrin F.Y., Brosseau C. Exploring carbon nanotubes/BaTiO3/Fe3O4 nanocomposites as microwave absorbers. Progress in Electromagnetics Research C, 2016, vol. 66, pp. 77-85.

21. Miyake T., Yamakawa T., Ohno N. Measurement of stress relaxation in broken fibers embedded in epoxy using Raman spectroscopy. Journal of Materials Science, 1998, vol. 33, no. 21, pp. 5177-5183.

22. Brooks T.M. Brinton I.I. Condition assessment of Kevlar composite materials using Raman spectroscopy. Diss. Candidate for the degree of Master of Science. University of Missouri, Columbia, 2007, $78 \mathrm{p}$.

23. Nemanich R.J., Solin S.A. First- and second-order Raman scattering from finite-size crystals of graphite. Physical Review B, 1979, vol. 20, no, 2, pp. 392-401.

24. Ivanov-Omsky V.I., Smorgonskaya E.A. Issedovanie uglerodnoy struktury kompozitnukh plenok a-C:H $\langle\mathrm{Cu}\rangle$ i $a-C: H<C o>$ metodom ramanovskoy spektroskopii [The study of carbon structure of composite films a-C:H<Cu> and $a-C: H<C o>$ by Raman spectroscopy method]. Fizika $i$ tekhnika poluprovodnikov, 2005, vol. 39, no. 8, pp. 970-975. (Rus)
25. Vašková H., Křesálek V. Quasi real-time monitoring of epoxy resin crosslinking via Raman microscopy. International journal of mathematical models and methods in applied sciences, 2011, vol. 5, no. 7, pp. 1197-1204.

26. Vajaiac E., Palade S., Pantazi A., Stefan A., Pelin G., Baran D., Ban C., Purica M., Meltzer V., Pincu E., Berbecaru C., Dragoman D. Dragoman. Mechanical properties of multiwall carbon nanotube-epoxy composites. Digest Journal of Nanomaterials and Biostructures, 2015, vol. 10 , no. 2 , pp. 359-369.

27. Ivanov E., Kotsilkova R., Krusteya E. Effect of processing on rheological properties and structure development of EPOXY/MWCNT nanocomposites. Journal of Nanoparticle Research, 2011, vol. 13, no. 8, pp. 3393-3403.

28. Ma W., Liu L., Zhang Zh., Yang R., Liu G., Zhang T., An X., Yi X., Ren Y., Niu Zh., Li J., Dong H., Zhou W., Ajayan P.M., Xie S. High-strength composite fibers: realizing true potential of carbon nanotubes in polymer matrix through continuous reticulate architecture and molecular level couplings. Nano Letters, 2009, vol. 9, no. 8, pp. 2855-2861.

29. Osswald S., Flahaut E., Ye H., Gogotsi Y. Elimination of D-band Raman spectra of double-wall carbon nanotubes by oxidation. Chemical Physics Letters, 2005, vol. 402, no. 4-6, pp. 422-427.

30. Koltynowicz T.N. Measurements station for frequency dielectric spectroscopy for nanocomposites and semiconductors. Journal of applied spectroscopy, 2015, vol. 82, no. 4, pp. 623-628. 